\title{
Desalinization of a salt-affected soil in plots of various sizes under two modes of water application
}

\author{
BY I. S. DAHIYA, K. S. GREWAL \\ Department of Soils, Haryana Agricultural University, Hissar, Haryana, India \\ R. ANLAUF AND J. RICHTER \\ Institut für Bodenkunde der Universität Hannover, Herrenhäuserstrasse 2, \\ D.3000 Hannover 21, Federal Republic of Qermany
}

(Received 18 April 1984)

\begin{abstract}
SUMMARY
Leaching in a salt-affected, permeable, sandy loam soil was evaluated under con. tinuous and intermittent ponding conditions in $2 \times 2 \mathrm{~m}\left(\mathrm{~S}_{1}\right), 4 \times 4 \mathrm{~m}\left(\mathrm{~S}_{2}\right)$ and $6 \times 6 \mathrm{~m}\left(\mathrm{~S}_{3}\right)$ plots. The soil contained large amounts of soluble salts throughout the profile to the water table, chiefly chlorides and sulphates of sodium, calcium and magnesium. The leaching curves did not differ significantly between $S_{1}, S_{2}$ and $S_{3}$ plots under continuous ponding but did under intermittent ponding. The leaching efficiency decreased sharply with increased plot size. The leaching efficiency in $S_{1}$ plots was significantly greater with intermittent than with continuous ponding, but the reverse was true in $S_{3}$ plots. The displacement of the resident soil solution in $S_{1}$ plots under intermittent ponding was nearly piston-like. With increased plot size, it tended to deviate from this behaviour. The leaching curves from $S_{3}$ plots (this size being reasonable in farmers' fields) were compared with those obtained from numerical solution of a simplified steady-state salt transport model. The model also included a source term, solubility rate constant, for the slightly soluble salts present in the experimental soil. The pore water velocity was estimated from field capacity and time-averaged infiltration rate. The effective dispersion coefficient and solubility rate constant were estimated by a least-squares minimization technique. A reasonably good agreement was obtained between simulated and experimental leaching curves. For practical purposes, this simple model may be adequate to predict leaching in salt-affected soils similar to the one under consideration.
\end{abstract}

\section{INTRODUCTION}

Problems of soil salinity are widespread in the world, both in regions with humid climates, e.g., Holland, Sweden, Hungary and the U.S.S.R., and in arid or semi-arid regions, e.g., the south-western U.S.A., India and Middle East (Elgabaly, 1971; Dahiya \& Dahiya, 1977). It is estimated that onethird of the irrigated land in the world is affected by these problems (Bresler, McNeal \& Carter, 1982). About $4 \times 10^{4}$ ha of land annually become unfit for agricultural production because of salinization problems (Evans, 1974).

Many salt-affected soils are saline-sodic throughout the soil profile with chlorides and sulphates of sodium, calcium and magnesium as soluble salts. Shallow and fluctuating water tables are responsible for the creation of such soils. Reclamation of these soils requires lessening of soluble salts in the root zone by leaching to a level safer to crops (Dahiya, 1978). A reliable quantitative estimate of $(a)$ the extent of leaching accomplished by a given quantity of water at disposal; and (b), conversely, the amount of water needed (leaching requirement) to accomplish the desired level of leaching is an important factor governing reclamation and management of these soils. Such an estimation would also be useful in planning and modifying present irrigation systems in these areas to srevent further salinity development. Empirical leaching curves and some leaching models, ranging from relatively simple to rather complex ones, have been found adequate to make such an estimation. A recent review by $\mathrm{Pal} \&$ Poonia (1982) surveys most of these empirical rela- 
tionships and models. A detailed account of them is given by Bresler et al. (1982) in their book on salt-affected soils.

In these studies, mostly conducted in soil columns (e.g. Dahiya \& Abrol, 1974; Kirda, Nielsen \& Biggar, 1974 ; Dahiya, Singh, Singh \& Hajrasuliha, 1980) and micro-plots in the fields (e.g. Miller, Biggar \& Nielsen, 1965; Oster, Willardson \& Hoffman, 1972; Dahiya, Malik \& Singh, 1981, 1982), the leaching efficiency was found to be significantly higher when water was ponded intermittently rather than continuously on the soil surface. In other studies, salt removal was, however, found to be independent of mode of water application (Leffelaar \& Sharma, 1977; Dahiya, Singh, Richter \& Singh, 1984).

In practice, reclamation of soils is carried out on large plots which are manageable on farmers: fields. Spatial variability of soil salinity, as also of other soil properties, increases with an increase in area (see review of Dahiya, Richter \& Malik, 1984). Thus, any attempt made on development of a reclamation technology for these soils based on the results of laboratory and micro-plot experiments would probably be fruitless unless the validity of such results was examined on practically manageable large plots. Also, application of leaching models in many practical situations on salt-affected soils is likely to be restricted by the confounding effect of the spatial structure of solute mobility in large fields (Dahiya, Richter \& Malik, 1984).

In the present study, leaching behaviour of a permeable, sandy loam soil having salt-laden pro- files extending to the water table (a situation met by most of the soils under consideration) was evaluated in plots of three different sizes under continuous and intermittent ponding conditions. The observed data were compared with those predicted with a simplified steady-state salt transport model.

\section{MATERIALS AND METHODS}

\section{Field experiment}

The experiment was conducted from January to February 1981 at Haryana Government Agricultural Farm, Hansi, situated in the south-west part of Haryana state in northern India. The area is almost flat: slope varies from 0.10 to $0.35 \%$. Canal irrigation has been practised for more than 50 years. The climate is semi-arid, with mean annual rainfall of $350 \mathrm{~mm}, 70 \%$ of which falls between July and September. The water table is highly fluctuating, varying from $1 \mathrm{~m}$ deep in September to several metres in June. The essential properties of the selected soil are given in Table 1. The soil is classified as Natric Camborthid.

Leaching was accomplished in the following plots: (1) $2 \times 2 \mathrm{~m}\left(\mathrm{~S}_{1}\right) ; 4 \times 4 \mathrm{~m}\left(\mathrm{~S}_{2}\right)$; and (3) $6 \times 6 \mathrm{~m}$ $\left(\mathrm{S}_{3}\right)$. The modes of water application were: (1) continuous ponding (CP) with $60 \mathrm{~cm}$ water; and (2) intermittent ponding (IP) with $60 \mathrm{~cm}$ water. In the latter case, $5 \mathrm{~cm}$ water was added on every alternate day. These treatments were replicated three times to give a total of 18 plots. A fairly uniform salty piece of land was selected by preliminary sampling

Table 1. Composition of soil

\begin{tabular}{|c|c|c|c|c|c|}
\hline \multirow{2}{*}{ Property } & \multicolumn{5}{|c|}{ Depth $(\mathrm{cm})$} \\
\hline & $0-20$ & $20-40$ & $40-60$ & $60-80$ & $80-100$ \\
\hline $\mathrm{pH}_{1: 2}$ & $7 \cdot 9$ & $8 \cdot 0$ & $8 \cdot 2$ & $8 \cdot 6$ & $8 \cdot 6$ \\
\hline $\mathrm{EC}_{1: 2}(\mathrm{mmhos} / \mathrm{cm})$ & $6 \cdot 1$ & $6 \cdot 5$ & $7 \cdot 0$ & $7 \cdot 3$ & $7 \cdot 1$ \\
\hline Texture & $\begin{array}{l}\text { Sandy } \\
\text { loam }\end{array}$ & $\begin{array}{l}\text { Sandy } \\
\text { loam }\end{array}$ & $\begin{array}{l}\text { Loamy } \\
\text { sand }\end{array}$ & $\begin{array}{l}\text { Loamy } \\
\text { sand }\end{array}$ & $\begin{array}{l}\text { Loamy } \\
\text { sand }\end{array}$ \\
\hline $\mathrm{CaCO}_{3}(\%)$ & 0.1 & 0.2 & $1 \cdot 6$ & $3 \cdot 6$ & $4 \cdot 8$ \\
\hline ESP & 39 & 46 & 52 & 55 & 58 \\
\hline$\overline{\mathrm{CEC}}$ (m-equiv/100 g) & $7 \cdot 2$ & $8 \cdot 0$ & 8.7 & $9 \cdot 6$ & $9 \cdot 8$ \\
\hline Bulk density $\left(\mathrm{g} / \mathrm{cm}^{3}\right)$ & $1 \cdot 64$ & $1 \cdot 56$ & $1 \cdot 52$ & $1 \cdot 50$ & $1 \cdot 47$ \\
\hline \multicolumn{6}{|c|}{$\begin{array}{l}\text { Soluble salts (m-equiv/l) } \\
\text { in } 1: 2 \text { soil-water extract }\end{array}$} \\
\hline Calcium & 21 & 18 & 11 & 6 & 4 \\
\hline Magnesium & 10 & 6 & 4 & 4 & 6 \\
\hline Sodium & 30 & 41 & $\mathbf{5 5}$ & 63 & 61 \\
\hline Chloride & 42 & 54 & 61 & 60 & 62 \\
\hline Sulphate & 19 & 11 & 9 & 13 & 9 \\
\hline Bicarbonate & 3 & 5 & 6 & 6 & 6 \\
\hline \multicolumn{6}{|c|}{ Water content $\left(\mathrm{cm}^{3} / \mathrm{cm}^{3}\right)$} \\
\hline Before leaching & $0 \cdot 196$ & 0.207 & 0.210 & $0 \cdot 216$ & 0.228 \\
\hline While leaching & 0.330 & 0.286 & 0.282 & 0.280 & 0.271 \\
\hline
\end{tabular}

Depth (cm) 
and plots of the required size were made on it in a randomized fashion. The coefficient of variation of salt content in this piece of land was 3.3-10.3\% for different depths. Bricks were laid down around each plot to avoid saline soil falling into it from the ridges. A channel was dug around each plot and water was added to it while leaching was in progress to minimize the lateral movement of water.

The soil had a very impermeable compact layer with a thickness of $10-15 \mathrm{~cm}$ below the fluffy salt layer present on the soil surface. This is mainly because of the fact that the salty piece of land was lying barren for the last several decades, as no crop can grow on it. The layer was broken up with a spade prior to the commencement of leaching. The plots were levelled sufficiently to give a uniform distribution of irrigation water. Leaching was accomplished with good quality canal water that contained a negligible amount of soluble salts.

Soil samples were collected before leaching started and after 10, 20,40 and $60 \mathrm{~cm}$ of water had infiltrated into the soil. Samples were taken to a depth of $100 \mathrm{~cm}$ at $20 \mathrm{~cm}$ intervals. Individual samples for a given depth taken at several positions in each plot were combined, and averages from three replicates are presented here. The bulk density was found by core sampling.

Soil samples were analysed for water content and electrical conductivity (EC) of $1: 2$ soil-water extract. From the EC values, concentration of total soluble salts in the soil solution was estimated (Richards, 1954).

\section{Model description}

In the system under consideration, the soil profile remains appreciably moist throughout the year. As can be seen from Table 1 , average water content prior to leaching was $0.21 \mathrm{~cm}^{3} / \mathrm{cm}^{3}$. This is because of the presence of $(a)$ hygroscopic salts in the soil; and $(b)$ shallow water table. The water content at greater depths remains quite constant in such soils even though irrigation or rainfall may change the water content distribution near the soil surface for some time. Also during leaching, profile water content was nearly constant. Hence, water movement through soil under such conditions may be considered steady (quasi-stationary). Previous field studics also support this assumption (Leffelaar \& Sharma, 1977; Khosla, Gupta \& Abrol, 1979; Dahiya et al. 1981, 1982; Dahiya, Malik \& Richter, 1983). The experimental (Table 1) and other such soils (Dahiya \& Dahiya, 1977) contain appreciable amounts of slightly soluble salts like gypsum and lime. Since such salts can greatly affect the concentration of total soluble salts in soil solution, their solubility was also accounted for in the transport model. The interaction of these salts with soil solution was assumed to be irreversible during leaching.

Movement of non-reactive solutes in onedimensional profile under steady-state conditions may be described by the convectivo-dispersive solute transport equation:

$$
\frac{\delta C}{\delta t}=D\left(\frac{\delta^{2} C}{\delta x^{2}}\right)-v \frac{\delta C}{\delta x}+K,
$$

where $C=$ soil solution salt concentration (mequiv $\left./ \mathrm{cm}^{3}\right), v=$ average pore water velocity $(\mathrm{cm} /$ day) given by Darcian flux $q$ (cm/day) divided by volumetric water content $\theta\left(\mathrm{cm}^{3} / \mathrm{cm}^{3}\right), D=$ effective dispersion coefficient $\left(\mathrm{cm}^{2} / \mathrm{day}\right), x=$ distance from the soil surface $(\mathrm{cm}), t=$ time (days), and $K=$ solubility rate constant for sparingly soluble salts (m-equiv/day).

We used here a simple explicit finite-difference solution of equation (1) as in an earlier report (Richter, Scharpf \& Wehrmann, 1978):

$$
\begin{array}{r}
\frac{C_{t+\Delta t}-C_{t}}{\Delta t}=D \frac{C_{x+\Delta x}-2 C_{x}+C_{x-\Delta x}}{\Delta x^{2}} \\
-v \frac{C_{x}-C_{x-\Delta x}}{\Delta x}+K
\end{array}
$$

to get $C_{t+\Delta t}$. The initial and boundary conditions consist of

$$
C(x>0,0)=C_{0}, \quad C\left(0, t_{t}>0\right)=0 .
$$

$C$ and $C_{0}$ are average values for the profile and these were reasonably uniform down the profile ('Table 1). The calculation process was formulated as Dialogprogram in BAsIC for a table (micro) computer.

Values of $v, D$ and $K$ in the model were determined as follows.

A time-averaged water flux rate, $q$, was determined from the total amount of water infiltrated divided by the total infiltration time. Cumulative infiltration was estimated by subtracting the value of cumulative pan evaporation from the total amount of water applied. Previous experience (e.g. Dahiya et al. 1981, 1982, 1983) as well as data from this study showed that irrespective of mode of water application, leaching in such structureless soils takes place at a volumetric water content nearly equivalent to field capacity, i.e. $\theta=\theta_{f c}$. For the present field, this value was $0.29 \mathrm{~cm}^{3} / \mathrm{cm}^{3}$ for $100 \mathrm{~cm}$ soil depth (Table 1). The use of these estimated values of $q$ and $\theta$ gave average pore water velocity of 8.3 and $35.9 \mathrm{~cm} /$ day for intermittent and continuous ponding respectively.

Because of the complex nature of solute transfer through porous media, which depends upon the geometric configuration of the pores, the soil water content, the flow velocity of soil water, the concentration of solutes and the composition of solutes, 

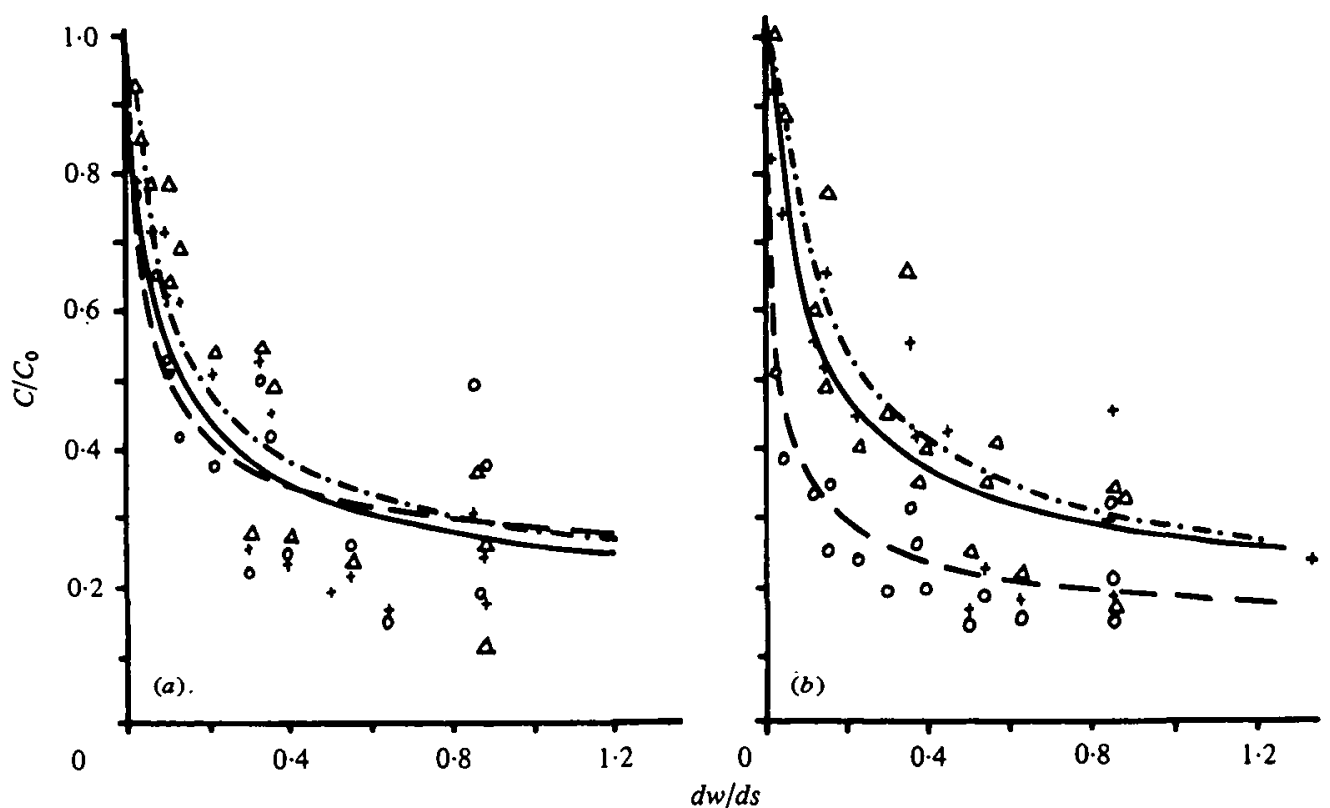

Fig. 1. Leaching curves showing effect of plot size $\left(\mathrm{S}_{1}, 2 \times 2 \mathrm{~m} ; \mathrm{S}_{2}, 4 \times 4 \mathrm{~m} ; \mathrm{S}_{3}, 6 \times 6 \mathrm{~m}\right)$ under $(a)$ continuous ponding (CP, and (b) intermittent ponding (IP). $\mathrm{S}_{1},--, 0 ; \mathrm{S}_{2},-,+; \mathrm{S}_{3},-\cdot-\cdot, \Delta$.

generally empirical relations are used to estimate $D$ (e.g. Frissel, Poolstra \& Reiniger, 1970; Rose \& Passioura, 1971; Amoozegar-Fard, Warrick \& Fuller, 1983). Using experimental data, we estimated $D$ and $K$ by a least-squares minimization technique. Values of $D$ thus obtained were 75 and $270 \mathrm{~cm}^{2} /$ day for intermittent and continuous ponding, respectively. The corresponding values of $K$ were 0.5 and $1.2 \mathrm{~m}$-equiv/day. We preferred this technique because others are time consuming and rather complicated.

\section{RESULTS AND DISCUSSION}

\section{Treatment effects}

The amount of variation (expressed as c.v.) between replicates ranged between 1.4 and $8.2 \%$ for salt content and 1.1 and $6.3 \%$ for water content for different treatments. For clarity, effectiveness of different treatments on leaching behavicur was examined by comparing the best fit leaching (desalinization) curves obtained by regression between $\mathrm{C} / \mathrm{C}_{0}$ and $d w / d s$. These curves are shown in Figs 1 and 2. Their regression equations with other statistical parameters appear in Table 2. Figure 1 also includes data points. Here, $d w$ is the total amount of leaching (drainage) water at successive samplings and $d s$ is the depth of soil. $C$ and $C_{0}$ are as defined earlier (equations 2 and 3 ). It is seen from Table 2 that the same equation fits the data reasonably well for all depths for a given treatment $(r=0.84-0 \cdot 93)$. A summary of statistical analysis of the data comparing different treatments is given in Table 3. For a still better comparison of treatment effects, $C / C_{0}$, calculated from regression equations of Table 2 at a given pore volume, $p$, is plotted against plot size in Fig. 3. Here, $p$ is given by $(d w / d s) / \theta_{f c}$.

Figure 1(a) compares leaching curves for plots $\mathrm{S}_{1}, \mathrm{~S}_{2}$ and $\mathrm{S}_{3}$ under continuous ponding (CP). It is seen that there was little effect of plot size on leaching behaviour of the experimental soil under this mode of water application. Leaching efficiency $\left(1-C / C_{0}\right)$ slightly decreased as plot size increased. This is further evident from Fig. 3. Table 3 (lines 1-3) shows that mean $C / C_{0}$ values for these treatments do not differ significantly from one another. The ineffectiveness of plot size under CP may be attributed to the continuous water standing on the soil surface. As a result of this, possible spatial variation in inflitration rate due to micro-relief effect in larger plots might have been minimum.

Figure $1(b)$ compares leaching curves for plots of different size under intermittent ponding (IP). It is seen that there was considerable difference between any two of the three leaching curves. Figure 3 further elucidates this fact. The leaching efficiency decreased sharply as plot size increased. The rate of this decrease might become zero with further increase in plot size $\left(>36 \mathrm{~m}^{2}\right)$. The means 

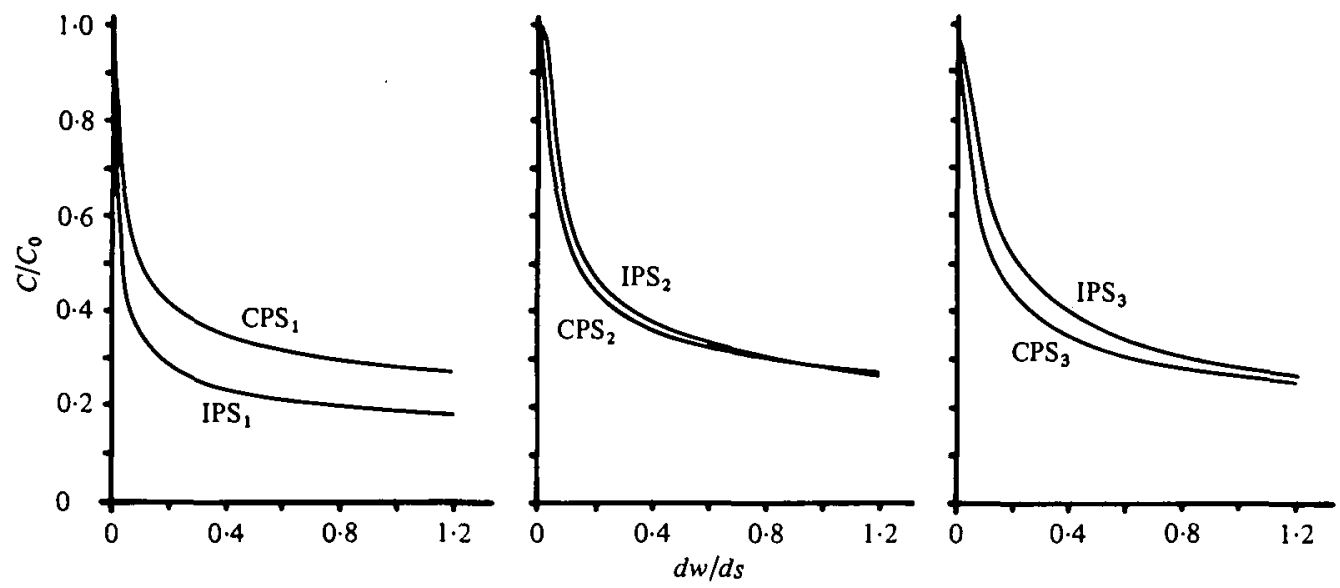

Fig 2. Leaching curves showing effect of modes of water application (CP, continuous ponding; IP, intermittent ponding) in plots of different sizes $\left(\mathrm{S}_{1}, 2 \times 2 \mathrm{~m} ; \mathrm{S}_{2}, 4 \times 4 \mathrm{~m} ; \mathrm{S}_{3}, 6 \times 6 \mathrm{~m}\right)$

Table 2. Best fit desalinization curves for different treatments

\begin{tabular}{|c|c|c|c|c|}
\hline \multirow[b]{2}{*}{ Treatment* } & \multirow[b]{2}{*}{ Regression equation } & \multicolumn{2}{|c|}{ Standard error of } & \multirow{2}{*}{$\begin{array}{l}\text { Correla- } \\
\text { tion co- } \\
\text { efficient }\end{array}$} \\
\hline & & Slope & Intercept & \\
\hline $\mathrm{CPS}_{1}$ & $C / C_{0}=0.095+0.190(d w / d s)^{-0.333}$ & 0.029 & 0.054 & 0.84 \\
\hline $\mathrm{CPS}_{2}$ & $C / C_{0}=0.064+0.216(d w / d s)^{-0.333}$ & 0.030 & 0.056 & 0.87 \\
\hline $\mathrm{CPS}_{3}$ & $C / C_{0}=0.019+0.246(d w / d s)^{-0.333}$ & 0.036 & 0.068 & 0.84 \\
\hline IPS $_{1}$ & $C / C_{0}=0.051+0.141(d w / d s)^{-0.333}$ & 0.019 & 0.032 & $0 \cdot 88$ \\
\hline $\mathrm{IPS}_{2}$ & $C / C_{0}=0.009+0.263(d w / d s)^{-0.333}$ & 0.035 & 0.062 & 0.86 \\
\hline $\mathrm{IPS}_{\mathbf{3}}$ & $C / C_{0}=-0.053+0.335(d w / d s)^{-0.933}$ & 0.031 & 0.054 & 0.92 \\
\hline $\mathrm{CPS}_{\mathbf{3}(\mathrm{cal})}$ & $C / C_{0}=-0.050+0.277(d w / d s)^{-0.333}$ & 0.032 & 0.059 & 0.91 \\
\hline IPS $_{3(\mathrm{cal})}$ & $C / C_{0}=-0.071+0.324(d w / d s)^{-0.333}$ & 0.031 & 0.053 & 0.93 \\
\hline
\end{tabular}

* CP, continuous ponding; IP, intermittent ponding; $S_{1}, 2 \times 2 \mathrm{~m}$ plot; $S_{2}, 4 \times 4 \mathrm{~m}$ plot; $S_{3}, 6 \times 6 \mathrm{~m}$ plot.

of any two curves differed significantly from each other (Table 3, lines 4-6). The possible reason for obtaining significantly lower leaching efficiency in larger plots $\left(S_{2}\right.$ and $S_{3}$ ) may be that in these plots there might have been a relatively larger effect of micro-relief on infiltration of intermittently applied water. After the addition of each increment of $5 \mathrm{~cm}$ water on alternate days, the water was concentrated in localized small depressions randomly distributed in these plots. This was because perfect levelling of them was not feasible. On the other hand, in small plots $\left(S_{1}\right)$, more or less perfect levelling was attained. As one would expcct, uniformly distributed irrigation would ultimately be more effective in leaching salts than would be nonuniformly distributed irrigation, all other conditions remaining equal. Recently, Bresler et al. (1982) have presented quantitative estimations of salt leaching in large fields under uniformly and nonuniformly distributed irrigation. For example, they estimated that for spatially uniform recharge rate, leaching to a desired level in a fictitious homo- geneous soil would be completed only $80 \mathrm{~h}$ after the commencement of irrigation. For the case with an abnormally high coefficient of variation for the recharge resulting from non-uniformly distributed irrigation, only $24 \%$ of the total area of the field was leached after $100 \mathrm{~h}$.

Curves in Fig. 2 show a comparison of the effects of modes of water application. This Figure and Table 3 (lines 7-9) show that leaching efficiency was significantly higher in $\mathrm{S}_{1}$, insignificantly lower in $S_{2}$ and significantly lower in $S_{3}$ plots with intermittent than with continuous ponding. Figure 3 shows these differences more clearly. As mentioned earlier, several previous workers also obtained more efficient salt leaching with intermittent than with continuous ponding in soil columns (e.g. Dahiya \& Abrol, 1974; Kirda et al. 1974; Dahiya, Singh, Singh \& Hajrasuliha, 1980) and $2 \times 2 \mathrm{~m}$ field plots (e.g. Dahiya et al. 1981, 1982). They argued that leaching intermittently to allow more time for movement of water through the small pores will improve the leaching efficiency in the soils. Also, 
Table 3. Statistical analysis of desalinization data $\left(C / C_{0}\right)$ for comparison of treatment effects

\begin{tabular}{|c|c|c|c|}
\hline Pairs* & $\begin{array}{c}\text { Mean } \\
\text { difference }\end{array}$ & $\begin{array}{l}\text { Standard } \\
\text { deviation } \\
\text { of mean } \\
\text { difference }\end{array}$ & $t_{\text {(cal) }} \dagger$ \\
\hline $\mathrm{CPS}_{1} / \mathrm{CPS}_{2}$ & -0.017 & 0.022 & 0.77 \\
\hline $\mathrm{CPS}_{1} / \mathrm{CPS}_{3}$ & -0.017 & 0.026 & 0.65 \\
\hline $\mathrm{CPS}_{2} / \mathrm{CPS}_{3}$ & -0.004 & 0.008 & 0.50 \\
\hline $\mathrm{IPS}_{1} / \mathrm{IPS}_{\mathbf{2}}$ & -0.145 & 0.027 & $5 \cdot 37$ \\
\hline $\mathrm{IPS}_{1} / \mathrm{IPS}_{3}$ & $-0 \cdot 185$ & $0 \cdot 040$ & $4 \cdot 63$ \\
\hline $\mathrm{IPS}_{2} / \mathrm{IPS}_{3}$ & -0.055 & 0.023 & $2 \cdot 40$ \\
\hline $\mathrm{CPS}_{1} / \mathrm{IPS}_{1}$ & $0 \cdot 128$ & 0.021 & $6 \cdot 10$ \\
\hline $\mathrm{CPS}_{2} / \mathrm{IPS}_{8}$ & 0.003 & 0.015 & 0.20 \\
\hline $\mathrm{CPS}_{3} / \mathrm{IPS}_{3}$ & -0.059 & $0 \cdot 023$ & $2 \cdot 57$ \\
\hline $\mathrm{CPS}_{3} / \mathrm{CPS}_{3(\mathrm{cal})}$ & 0.020 & 0.031 & 0.65 \\
\hline $\mathrm{IPS}_{3} / \mathrm{IPS}_{\mathrm{g}(\mathrm{cal})}$ & 0.039 & 0.036 & 1.08 \\
\hline
\end{tabular}

intermittent leaching may give time for solutes to diffuse from the less mobile to the mobile water in between successive applications of water. On the other hand, since the intermittently applied water was not uniformly distributed over the soil surface in the larger plots $\left(S_{2}\right.$ and $\left.S_{3}\right)$, the leaching efficiency was lower in these plots with intermittent than with continuous ponding.

These results suggest that under practical situations in which reclamation is carried out in large plots, the practice of leaching salts with intermittent ponding would be less effective. Such a practice would require more labour and time than single continuous application of water. Thus, leaching of selts down into the soil with a single heavy irrigation would be more desirable.

\section{Nature of soil solution displacement}

Further examination of Fig. 3 indicates that in $2 \times 2 \mathrm{~m}\left(\mathrm{~S}_{1}\right)$ plots under IP, salt leaching from the soil profile at one pore volume was $(1-0 \cdot 26) 100=$ $74 \%$, i.e. $\left(1-C / C_{0}\right) 100$. Some recent studies, conducted in this part of India, showed that one pore volume of water displaced $80-94 \%$ of the salts from the soil profile in $2 \times 2 \mathrm{~m}$ plots (Dahiya $e t$ al. 1981,1982 ) and small infiltrometers (Leffelaar \& Sharma, 1977; Khosla et al. 1979; Dahiya et al. 1983). Under ideal piston flow conditions, the resident soil solution would be displaced, or pushed, by the leaching water right in front of it, i.e. at one pore volume $100 \%$ salt removal would oceur. Removal of $74-94 \%$ of salts at one pore volume in these studies indicated that a piston-like displacement of soil solution occurred. This behaviour has also been reported by Smiles et al. $(1978,1981)$, Dahiya, Singh, Richter \& Singh (1984) and many

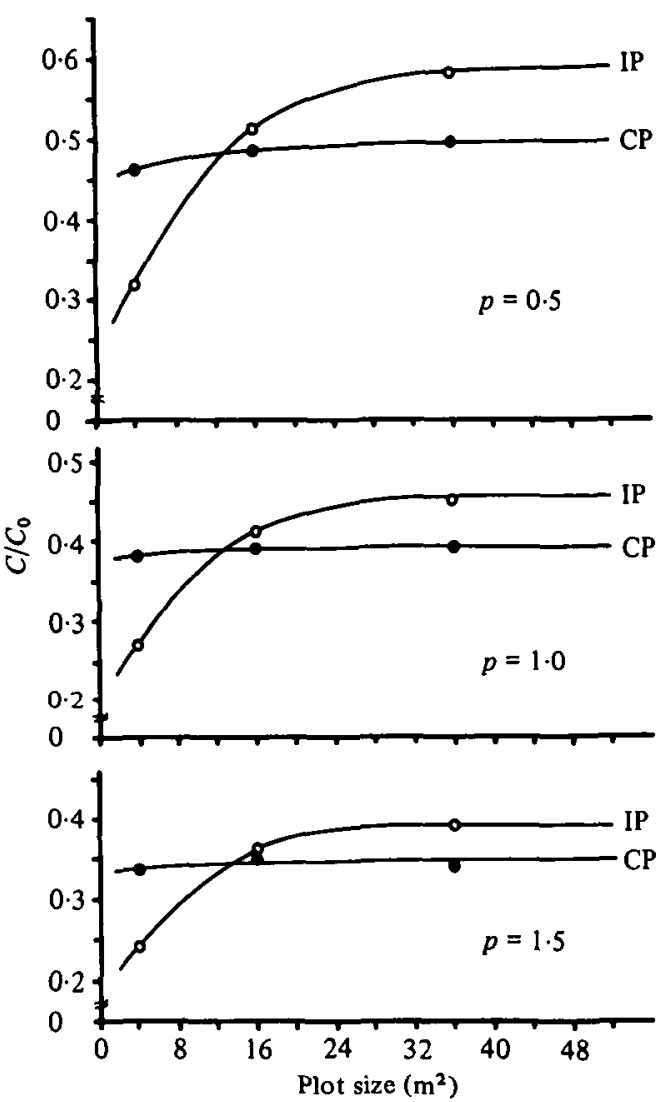

Fig. 3. Values of $C / C_{0}$ at a given pore volume $(p)$ plotted against plot size. CP, continuous ponding; IP, intermittent ponding.

others in laboratory columns containing nonaggregated soils, as the case in the present study.

In other plots, salt removal at one pore volume varied from 55 to $62 \%$ (Fig. 3). This indicated that, in general, as plot size increased, salt displacement tended to deviate from piston-like flow. This means that there was not as complete leaching in these plots as in $2 \times 2 \mathrm{~m}$ plots under IP. These results and those obtained in field studies by other workers (e.g. Talsma, 1967; Wild \& Babiker, 1976; Addis. cott, 1977) show that, in general, a piston-like displacement of soil solution would not occur in practical situations.

\section{Comparison with model predictions}

We have seen from Fig. 3 that the effect of plot size on leaching might beome insignificant irrespective of mode of water application when the plot size becomes greater than $6 \times 6 \mathrm{~m}$. Thus, this plot size may be considered as the minimum plot size for the experimental soil for practical purposes. 


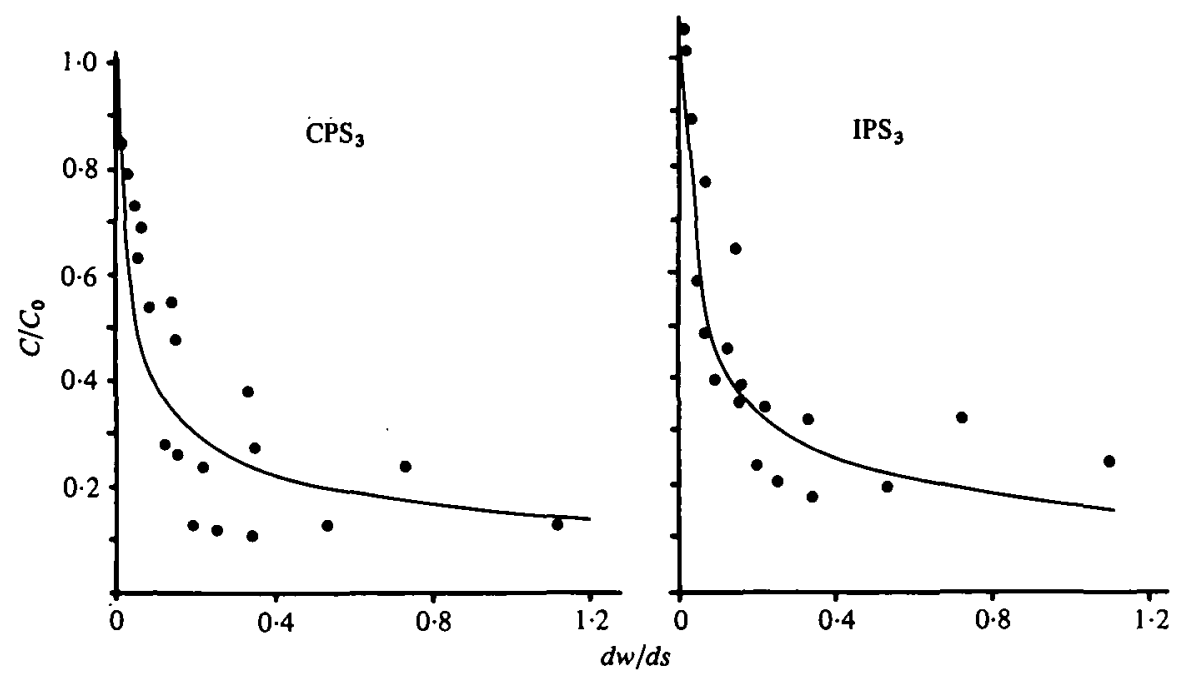

Fig. 4. Calculated (solid lines) and observed (points) leaching data for $S_{3}$ plots $(6 \times 6 \mathrm{~m})$ under continuous (CP) and intermittent (IP) ponding.

Hence, leaching curves only for $\mathrm{CPS}_{3}$ and IPS $\mathrm{S}_{3}$ plots were compared with predicted ones. Figure 4 shows this comparison. The predicted curve passed fairly well through the experimental points. Thus, the agreement was good through the whole range of desalinization. Statistically, the predicted and experimental data did not differ significantly from each other as can be seen from Table 3 (lines 10 and 11). In the final stages of leaching, the simulation showed slightly higher leaching efficiency than did the experimental data (compare regression equa-

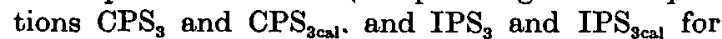
high values of $d w / d s$ ). This lack of agreement may partly be attributed to the incomplete leaching as a result of a dead-end-pore effect as suggested by Dahiya \& Abrol (1973) and Dahiya, Abrol \& Hajrasuliha (1980). According to them, the flow in unsaturated state produces a configuration of water distribution in a manner that there are certain localized volumes of stagnant water which are connected to the main stream through very thin films or narrow channels in which the transverse hydrodynamic dispersion is reduced considerably. Whereas in the theoretical model, mixing of the solutions (one added and the other already present) has been envisaged, there would always be partial mixing of the solutions due to the presence of the so-called dead or blocked pores. This would, evidently, give rise to higher experimental values than expected on the basis of complete mixing.

Since the agreement between the simulated and observed data is good, it is evident that a good prediction can be made using the model for practical situations. More comprehensive models are available for predictive purposes. However, owing to the complicated nature of such models, practical application is often difficult. The present model is much simpler to apply than others.

Thanks are due to the Indian Council of Agricultural Research, New Delhi for providing financial assistance to $\mathrm{Mr} \mathrm{K}$. S. Grewal for carrying out the experiment. Dr I. S. Dahiya and Mr R. Anlauf are grateful, respectively, to the Alexander von Humboldt Foundation, Bonn, Federal Republic of Germany, and the European Economic Community, Brussels, Belgium for providing financial assistance during the period in which the manuscript was prepared. Miss Ulrike Piepr is thanked for tracing the graphs.

\section{REFERENCES}

Addiscotr, T. M. (1977). A simple computer model for leaching in structured soils. Journal of Soil Science 28, 554-563.

Amoozegar-Fard, A., Warrick, A. W. \& Fuller, W. H. (1983). A simplified model for solute movement through soils. Soil Science Society of America Journal 47, 1047-1049.
Bresler, E., McNeal, B. L. \& Carter, D. L. (1982). Saline and Sodic Soils: Principles-Dynamics-Modeling. Berlin, Heidelberg, New York: Springer-Verlag.

DahiYA, I. S. (1978). Salt-affected soils in India. III. How to live with them. Agriculture and AgroIndustries Journal, Bombay 11 (8), 17-26. 11 (9), 17-24, 11 (10), 17-23. 
Dahiya, I. S. \& ABrol, I. P. (1973). Dynamics of calcium-sodium exchange under unsaturated flow conditions. Communications in Soil Science and Plant Analysis 4, 443-453.

DahiYa, I. S. \& ABrol, I. P. (1974). The redistribution of surface salts by transient and steady infiltration of water into dry soils. Journal of Indian Society of Soil Science 22, 209-216.

Dafrya, I. S., Abrol, I. P. \& Hajrasuliha, S. (1980). Modeling transport of reactive solutes in saline-sodic soils rich in soluble carbonates. Agriculsural Water Management 3, 3-16.

DamiYA, I. S. \& \& DahiYA, S. S. (1977). Salt-affected soils in India. I. Their origin, occurrence and charac. teristics. Agriculture and Agro-Industries Journal, Bombay 10 (1), 11-16.

DahiYa, I. S., MaIIK, R. S. \& Richter, J. (1983). Testing of simple leaching models in a field soil. International Journal of Tropical Agriculture 1, 193202.

Dahiya, I. S., Malik, R. S. \& Singh, M. (1981). Field studies on leaching behaviour of a highly saline-sodic soil under two modes of water application in the presence of crops. Journal of Agricultural Science, Cambridge 97, 383-389.

Dahrya, I. S., Malik, R. S. \& Singh, M. (1982). Re. claiming a saline-sodic, sandy loam soil under rice production. Agricultural Water Management 5, 61-72.

DahiYa, I. S., Richter, J. \& MaLik, R. S. (1984). Soil spatial variability : a reviow. International Journal of Tropical Agriculture 2, 1-102.

Dahiya, I. S., Singh, M., Richter, J. \& Singh, M. (1984). Leaching of soluble salt during infiltration and redistribution. Irrigation Science 5, 15-24.

Dahiya, I. S., Singh, M., Singh, M. \& Hajrasuliha, S. (1980). Simultaneous transport of surface applied salts and water through unsaturated soils as affected by infiltration, redistribution and evaporation. Soil Science Society of America Journal 44, 223-228.

Elaabaly, M. M. (1971). Reclamation and Management of Salt Affected Soils. Regional Seminar on Methods of Amelioration of Saline and Alkali Soik, Bagdad. F.A.O. Irrigation and Drainage Paper no. 7, pp. 50-59.

Evans, N. H. (1974). Finding knowledge gaps: the key of salinity control solutions. In Salinity in Water Resources (ed. J. E. Flack and C. W. Howe). Boulder, Colorado: Merriman.

Frissed, M. L., Poelstra, P. \& Reiniaen, P. (1970).
Chromatographic transport through soils. III. A simulation method for the evaluation of the ap. parent diffusion coefficient in undisturbed soils with tritiated water. Plant and Soil 33, 161-176.

Krosia, B. K., Gupta, R. K. \& ABrol, I. P. (1979). Salt leaching and the effect of gypsum application in a saline-sodic soil. Agricultural Water Management 2, 193-202.

Kirda, C., Nielsen, D. R. \& BigaAR, J. W. (1974). The combined effect of infiltration and redistribution on leaching. Soil Science 117, 323-330.

Leffelaar, P. A. \& Sharma, R. P. (1977). Leaching of a highly saline-sodic soil. Journal of Hydrology 32, 203-218.

Miller, R. J., Biggar, J. W. \& Nielsen, D. R. (1965). Chloride displacement in Panoche clay loam in relation to water movement and distribution. Water Resources Research 1, 63-73.

Oster, J. D., Willardson, L. S. \& Hoffman, G. J. (1972). Sprinkling and ponding techniques for reclaiming saline soils. Transactions of American Society of Agricultural Engineers 15, $1115-1117$.

PaL, R. \& Poonia, S. R. (1982). Predictive approaches for solute transport in soils. Journal of Scientific and Industrial Research, New Delhi 41, 117-130.

RICHARDS, L. A. (1954). Diagnosis and Improvement of Saline and Alkali Soils. United States Department of Agriculture Handbook no. 60.

Richter, J., ScharpF, H. C. \& WehrmanN, J. (1978). Simulation der winterlichen Nitratverlagerung in Böden. Plant and Soil 49, 381-393.

Rose, D. A. \& Passioura, J.B. (1971). The analysis of experiments on hydrodynamic dispersion. Soil Science 111, 252-257.

Smiles, D. E., Perroux, K. M., Zegelin, S. J. \& RaATs, P. A. C. (1981). Hydrodynamic dispersion during constant rate absorption of water by soil. Soil Science Society of America Journal 45, 453-458.

Smiles, D. E., Philip, J. R., KNight, J. H. \& Elrick, D. E. (1978). Hydrodynamic dispersion during ab. sorption of water by soil. Soil Science Society of America Journal 42, 229-236.

Talsma, T. (1967). Leaching of the tile-drained saline soils. Australian Journal of Soil Research 5, 37-46.

WILD, A. \& BabIker, I. A. (1976). The asymmetric leaching pattern of nitrate and chloride in a loamy sand under field conditions. Journal of Soil Science 27, 460-466. 